\title{
Quercetin Protects Against Stress-Induced Anxiety- and Depression- Like Behavior and Improves Memory in Male Mice
}

\author{
N. SAMAD ${ }^{1}$, A. SALEEM ${ }^{1}$, F. YASMIN ${ }^{2}$, M. A. SHEHZAD ${ }^{3}$ \\ ${ }^{1}$ Department of Biochemistry, Bahauddin Zakariya University, Multan, Pakistan, ${ }^{2}$ Department of \\ Food and Biomedical Engineering, NED University of Engineering and Technology, Karachi, \\ Pakistan, ${ }^{3}$ Department of Statistics, Bahauddin Zakariya University, Multan, Pakistan
}

Received October 14, 2017

Accepted May 23, 2018

On-line July 25, 2018

\section{Summary}

The present study evaluates the protective role of Quercetin (Quer), against immobilization stress- induced anxiety, depression and cognition alteration in mice using behavioral and biochemical parameters. 24 adult Albino mice were distributed into 2 groups vehicle $(\mathrm{n}=12 ; 1 \mathrm{ml} / \mathrm{kg})$ and Quer injected $(\mathrm{n}=12$; $20 \mathrm{mg} / \mathrm{kg} / \mathrm{ml}$ ). The animals received their respective treatment for 14 days. On day 15, after the drug administration, animals were sub-divided into 4 groups $(n=6)$; (i) unstressed + vehicle; (ii) stressed + vehicle; (iii) unstressed + Quer; (iv) stressed + Quer. On day 16, $24 \mathrm{~h}$ after the immobilization stress behavioral activities (light-dark activity, elevated plus maze, Morris water maze, and forced swim test) monitored and then animals were decapitated $1 \mathrm{~h}$ after the drug administration. Brain samples were collected for biochemical (antioxidant enzymes, AChE, ACh, 5-HT and its metabolite) analysis. The present study indicates the Quer reversed the stress-induced anxiety and depression, in addition, memory performance was more enhanced in stressed group. Following the treatment of Quer, stress-induced elevation of lipid peroxidation and suppression of antioxidant enzymes were also reversed. Administration of Quer decreased AChE in unstressed, while levels of acetylcholine were increased in vehicle and Quer treated stressed animals. The metabolism of 5-HT was increased in Quer treated stressed than unstressed animals. In conclusion, the present finding showed that Quer could prevent the impairment of antioxidant enzymes and also regulate the serotonergic and cholinergic neurotransmission and produce antianxiety, antidepressant effect and enhance memory following $2 \mathrm{~h}$ immobilization stress in mice.

\author{
Key words \\ Quercetin • Immobilization stress • Antioxidant enzymes • \\ Serotonin • Acetylcholine
}

\section{Corresponding author}

N. Samad, Department of Biochemistry, Bahauddin Zakariya University, 60800-Multan, Pakistan. E-mail: noreen.samad@bzu.edu.pk

\section{Introduction}

Stress can be characterized as physical and psychological alterations that upset the homeostasis and the equilibrium of organisms. It is recognized as one of the main reasons of a number of diseases (Borys 2008). Common stress symptoms include touchiness, muscular tension, lack of concentration and a range of bodily reactions, such as headaches, increased cardiac activity, hypertension, etc. (Alves et al. 2007) Studies with short term exposure to stress have been shown to assist cognition both in animals (Oitzl et al. 2001, Samad et al. 2017) and humans (Cahill et al. 2003). This enhance in memory has been ascribed to various glands secretions (hormones) and neuronal release (neurotransmitters) under stress condition. Previously it has reported that both sympathetic nervous system and hypothalamicpituitary-adrenal (HPA) axis have a vital role in memory amalgamation following the experience of stress circumstance (Joëls et al. 2006). Acute immobilization stress has reported to change locomotor activity and cause anxiety (Kumar et al. 2010, Haraguchi et al. 2012). 
Immobilization/restraint stress is one of various models that is most commonly employed, as it effectively mimics potent physical and psychological stress (Lucas et al. 2007). These models are linked with increased free radical production and altered antioxidant enzyme activities (Gümüs et al. 2002). Restraint stress prompts cellular pathways that lead to raise production of free radicals (Tseilikman et al. 2009). The central nervous system has conventionally been considered as a target site for free radical damage because brain contains abundant lipid content and consumes high amount of oxygen (Halliwell and Gutteridge 1985).

The psychological deficits linked with acute stressful events may prevent using therapeutic strategies involving medicinal and dietary phyto-antioxidants. One such neutraceutical is quercetin (Quer), which is belong to flavonoids - secondary metabolites of plants. Since flavonoids are present in food and medicinal plants, they are consumed by humans. Their main sources are vegetables, fruits, tea and wine and the average daily intake of flavonoids by humans on a normal diet is 1-2 g/day (Havsteen 2002). These compounds have reported to have beneficial effects in numerous diseases in humans, including cancer and cardiovascular diseases. In addition, their antioxidant, anti-inflammatory, antitumoral and antiviral properties were also noted (Fernandez et al. 2006). The ability of flavonoids (Quer) to pass the blood-brain barrier causes numerous effects on the central nervous system, which revealed both in the in vitro and in vivo studies (Jager and Saaby 2011). Moreover, they might be ligands for benzodiazepine binding sites of the $\gamma$-aminobutyric acid type A (GABAA) receptor, which confirmed by behavioral effects in animal models of anxiety, sedation and convulsions. Flavonoids might also affect the activity of other neurotransmitter systems. It was revealed that Quer modulate activity of adenosine, serotonin, glycine and acetylcholine receptors (Lee et al. 2011).

Quer exhibit neuroprotective properties in animal models, i.e. it improve memory and learning abilities (Nassiri-Asl et al. 2010b, Nassiri-Asl et al. 2013a, Tongjaroenbuangam et al. 2011) and have antidepressant and anti-stress (Kawabata et al. 2010) action as compound of extracts from herbs (Herrera-Ruiz et al. 2011, Machado et al. 2008). It also improved the behavioral performance of mice fed a high-cholesterol diet both in the step-through test and the Morris water maze task. This effect seemed to be connected to inhibition of AMP-activated protein kinase (AMPK) by
Quer and might be utilized in therapy and prevention of Alzheimer's disease (Lu et al. 2010). Quer has been examined to protect biological membrane from peroxidative damage. The inhibition of lipid peroxidation by Quer mainly exhibited due to its scavenging ability of free reactive radical (Mercer et al. 2005, Nabavi et al. 2015, Sharma et al. 2015). Quer is regarded as a potent inducer of detoxifying enzymes such as super oxide dismutase, catalase and glutathione peroxidase and dissuade lipid peroxidation thereby ameliorates oxidative stress (Mercer et al. 2005, Haleagrahara et al. 2009). In several studies it has been used as an antioxidant to reduce anxiety-like behavior (Wattanathorn et al. 2007) and increased cognitive dysfunction in diabetic rats (Maciel et al. 2016) inhibits apoptosis, and improves memory function in animal model of Alzheimer's disease (Mesram et al. 2017) and also prevents D-galactose induced aging (Sun et al. 2007). It has also been reported that Quer has a role in alleviating stress and depression like symptoms by enhancing antioxidant enzyme (Yoshino et al. 2011, Kumar and Goyal 2008) and other neurological disorders associated with cadmium intoxication (Abdalla et al. 2013, Abdalla et al. 2014). Recently, it is reported that Quer can improves serotonergic and cholinergic functions following repeated treatment (Liaqat et al. 2018).

Based on the antioxidant effects of Quer, we hypothesized that, being a flavonoid, Quer may enhance the memory function, reduce anxiety and depression like behavior following $2 \mathrm{~h}$ immobilization stress. To elucidate this issue, the current study aimed to determine the effects of repeated administration of Quer on cognitive function, stress responses, cholinergic function and serotonin metabolism in animals following acute immobilization stress

\section{Methods}

Animals

Male Albino Wistar mice with mean weight $20 \pm 5 \mathrm{~g}$, bred in Animal House facility of University of Lahore, Lahore, Pakistan, were used for the experiment. Animals were caged individually in plastic cages under standard laboratory conditions and maintained on a $12 \mathrm{~h}$ light/dark cycle. Animals had access to cubes of standard rodent diet and tap water ad libitum for 3 days prior to acclimatization. The experimental protocols were approved by the institutional ethics and animal care committee and performed in strict accordance with National Institute of 
Health Guide for Care and Use of Laboratory Animals (Publication No. 85-23, revised 1985).

\section{Chemicals and reagents}

Thiobarbituric acid (TBA), $\mathrm{H}_{2} \mathrm{O}_{2}$ stock (35\%) solution, nitroblue tetrazolium (NBT), trichloroacetic acid (TCA) and Dithio-bisnitrobenzoic acid (DTNB) were purchased from British Drug House (BDH, Dorset, UK). Acetylthiocholine (ATC), hydroxylamine hydrochloride and all other analytical grade reagents were purchased from Sigma Chemical Co. (St. Louis, MO, USA).

\section{Treatment schedule}

The experiment performed in a non-blind fashion as previously reported (Samad and Haleem 2009). Twenty-four animals randomly divided into two equal groups of 12 each. Test group received Quer dissolved in $25 \%$ ethanol $(20 \mathrm{mg} / \mathrm{ml} / \mathrm{kg} /$; i.p. $)$, while the other control group was injected with vehicle $(25 \%$ ethanol) (1 ml/kg; i.p.) as reported previously (Maciel et al. 2016). The animal received this treatment for 14 days.

On day 15, animals were further divided into four groups, of six each were assigned as (i) unstressed + vehicle; (ii) stressed + vehicle; (iii) unstressed + Quer (iv) stressed + Quer. The stressed group was accommodated in a separate room for immobilization stress for $2 \mathrm{~h}$.

Behavioral activities [Forced swim test (FST), light dark activity (LDA), elevated plus maze (EPM) and Morris water maze (MWM) test] were monitored $24 \mathrm{~h}$ after the immobilization stress (on day 16). There was 60 min break between each activity in which animals were kept back in their home cages to avoid overlapping. Behavioral activities of control mice were also monitored at the same time.

On day 16, after behavioral tests animals were decapitated and their brains were collected. All brain samples were instantly kept freeze at $70^{\circ} \mathrm{C}$ for biochemical assays.

\section{Immobilization stress}

The animals were restrained on wire grids of $10^{\prime \prime} \times 9^{\prime \prime}$ fitted with a Perspex plate of $9^{\prime \prime} \times 6.5^{\prime \prime}$. Restraining procedure was same as described earlier (Samad and Haleem 2009, Samad et al. 2006). Immobilization was produced by pressing the fore legs of the rats through the gaps in the metal grids and taping them together with Zinc Oxide plaster tape. Hind limbs were also taped and the head of animal rested on the Perspex plate.

\section{Behavioral tests}

\section{Light-dark activity (LDA) test}

The test was conducted in a locally-made compartment box (Samad and Haleem 2009). The compartment of equal size $(26 \times 26 \times 26 \mathrm{~cm})$, with an access $(12 \times 12 \mathrm{~cm})$ between the compartments, differed in their sensory properties. Walls of on compartment were light (transparent) and other dark (Black). A rat placed in this box expected to pass more time in the dark compartment. To determine the activity a rat was introduced via the dark compartment of the box. Time spent in the light compartment was monitored with stop watch for a cut off time of $5 \mathrm{~min}$.

\section{Elevated plus maze (EPM) test}

Anxiety was assessed by EPM according to the method as described by Naqvi et al. (2012). The apparatus used in the present study was consisted of two closed arms and two open arms with same dimensions $(50 \times 10 \mathrm{~cm})$. Close arms were enclosed by $40 \mathrm{~cm}$ high walls. The arms were connected with a central square $(10 \times 10 \mathrm{~cm})$ to give the apparatus a plus sign appearance. The maze was elevated $60 \mathrm{~cm}$ above the floor. To monitor the activity, mice were individually placed in the central square facing an enclosed arm and the time spent in open arm was recorded manually for a cut off time of $5 \mathrm{~min}$.

\section{Forced swimming test (FST)}

The FST apparatus comprised of a glass tank with $56 \mathrm{~cm}$ height and $30 \mathrm{~cm}$ width, which contained water at the height of $22 \mathrm{~cm}$ and temperature of $25^{\circ} \mathrm{C}$. In this glass tank animals were individually forced to swim for $5 \mathrm{~min}$. The height of water was selected so that animal was prevented from touching the bottom of the glass tank and also to prevent its escape from the glass tank. The FST is commonly used as standard pharmacological model for evaluating depression like symptoms in rat/mice (Porsolt et al. 1997). When the mice are placed in an inescapable chamber which is filled with water then the development of the state of immobility reflects the cessation of persistent escape directed behavior. In this test animal's swimming behavior was monitored which can be defined as movement throughout the swim chamber (glass tank). The immobility time was monitored manually. The animal is considered immobile when it makes no further attempts to escape and only tries to keep its head above the water. 


\section{Morris water maze (MWM) test}

MWM test was performed to examine the effects on spatial memory as described by Morris in 1981. This is a well-known, conventional cognitive test which requires an animal to use spatial learning and memory to locate a hidden platform just below the surface of a circular pool of water and also to remember its location as in the previous trial. It is reported that the animal uses cues in order to locate the hidden platform. The maze used for rats is same as described earlier (Haider et al. 2011). It is a circular pool of water with a diameter of $45 \mathrm{~cm}$, height of $37 \mathrm{~cm}$ and depth of water is $12 \mathrm{~cm}$. The metal pool painted white on the inner side and a wooden escape platform with a surface diameter of $8 \mathrm{~cm}$ was placed $2 \mathrm{~cm}$ below the surface of water during water maze training. The pool was filled with milky water $\left(23 \pm 2{ }^{\circ} \mathrm{C}\right)$ in order to obscure the platform. In our experiment we have assessed the acquisition short-term memory and long term memory in terms of latency to locate the escape platform. The test is based upon two phases; the training phase and the test phase, while starting position was same in both phases. The cut off time was $2 \mathrm{~min}$ for each session. Memory functions of rats were tested by noting the retention latency. Initially the training session was performed during which each mice placed into the water facing towards the wall of the tank. After placing, $120 \mathrm{~s}$ were given to each animal to find and mount onto the hidden platform. If the mice located the platform it was allowed to stay on it for $10 \mathrm{~s}$. If it failed to locate the platform during the allocated time then it was guided gently to the platform and that session repeated twice. The assessment of memory was performed immediately after (acquisition) and $60 \mathrm{~min}$ (short term memory) following training session during which escape latency was monitored manually.

\section{Biochemical parameters}

All the animals were decapitated on the same day immediately after behavioral analysis. The whole brains were removed, rinsed in isotonic saline, and weighed. A $10 \%(\mathrm{w} / \mathrm{v})$ tissue homogenate was prepared with $0.1 \mathrm{M}$ phosphate buffer ( $\mathrm{pH} 7.4$ ) which was obtained by centrifugation at $12,000 \times \mathrm{g}$ for $20 \mathrm{~min}$ at $4{ }^{\circ} \mathrm{C}$ for biochemical estimations

\section{Determination of malondialdehyde (MDA) content}

Estimation of lipid peroxidation was essentially the same as described by Chow and Tappel (1972) with slight modifications. In a reaction mixture $300 \mu 1$ homogenate was taken and $2 \mathrm{ml}$ of TCA (15\%)-TBA $(0.375 \%)$ mixture was added. The mixture was boiled for $20 \mathrm{~min}$ in water bath, cooled with ice cold water at $4{ }^{\circ} \mathrm{C}$ and then centrifuged at $3,500 \mathrm{rpm}$ for $10 \mathrm{~min}$. Supernatant of light pink color was then collected and absorbance was taken at $532 \mathrm{~nm}$. Lipid peroxidation was expressed as $\mathrm{mM}$ of $\mathrm{MDA} / \mathrm{g}$ of brain tissue.

\section{Determination of catalase (CAT)}

CAT was estimated using a previously reported method (Pari and Latha 2004). Brain homogenate (10\%) in $0.01 \mathrm{M}$ phosphate buffer ( $\mathrm{pH} 7.0)$ was prepared and filtered. Then $0.1 \mathrm{ml}$ of filtrate was mixed with $1.4 \mathrm{ml}$ of reaction mixture that contained $0.4 \mathrm{ml}$ of $2 \mathrm{M}$ hydrogen peroxide and $1 \mathrm{ml}$ of same phosphate buffer. The reaction was terminated after $1 \mathrm{~min}$ by adding $2.0 \mathrm{ml}$ of dichromate-acetic acid reagent. Blank contained distilled water in place of filtrate. The absorbance of both test and blank were measured at $620 \mathrm{~nm}$ to calculate percent inhibition of CAT.

\section{Determination of glutathione peroxidase (GPx) activity}

GPx activity was measured by the procedure of Flohe and Gunzler (1984). One ml of reaction mixture was prepared which contained $0.3 \mathrm{ml}$ of phosphate buffer (0.1 M, pH 7.4), $0.2 \mathrm{ml}$ of reduced glutathione (2 mM), $0.1 \mathrm{ml}$ of sodium azide $(10 \mathrm{mM}), 0.1 \mathrm{ml}$ of $\mathrm{H}_{2} \mathrm{O}_{2}(1 \mathrm{mM})$, and $0.3 \mathrm{ml}$ of brain supernatant. After incubation at $37^{\circ} \mathrm{C}$ for $15 \mathrm{~min}$, reaction was terminated by addition of $0.5 \mathrm{ml}$ $5 \%$ TCA. Tubes were centrifuged at $1,500 \times \mathrm{g}$ for $5 \mathrm{~min}$, and supernatant was collected. Phosphate buffer $0.2 \mathrm{ml}$ (0.1 M, pH 7.4) and DTNB $0.7 \mathrm{ml}(0.4 \mathrm{mg} / \mathrm{ml})$ were added to $0.1 \mathrm{ml}$ of reaction supernatant. After mixing, absorbance was recorded at $420 \mathrm{~nm}$. Activity of GPx was expressed as $\mu \mathrm{mol} / \mathrm{min} / \mathrm{g}$ of brain.

\section{Determination of superoxide dismutase (SOD)}

The SOD was estimated by the method (Naskar et al. 2010). An aliquot of brain homogenate (10\%) was treated with $0.75 \mathrm{ml}$ of ethanol and $0.15 \mathrm{ml}$ of ice chilled chloroform then centrifuged. Then $0.5 \mathrm{ml}$ of EDTA $(0.6 \mathrm{mM})$ and $1.0 \mathrm{ml}$ of carbonate-bicarbonate $(0.1 \mathrm{M}$; $\mathrm{pH} 10.2$ ) buffer was added in $0.5 \mathrm{ml}$ of supernatant. The reaction was started by adding $0.5 \mathrm{ml}$ of epinephrine $(1.8 \mathrm{mM})$ and the absorbance was measured for $3 \mathrm{~min}$ at $480 \mathrm{~nm}$. Blank contained all reagents except supernatant. Finally, percent inhibition of SOD was calculated. 


\section{Determination of brain acetylcholine (Ach) content}

The tissue acetylcholine content was estimated by the method of Hestrin (1949) as described by Augustinson (1957). The tissue sample was boiled to inactivate the enzyme and release the bound Ach which reacts with ferric chloride and the brown color developed was read at $540 \mathrm{~nm}$ against the reagent blank. The concentration of Ach was expressed as $\mu \mathrm{mol} / \mathrm{g}$ of brain tissue.

\section{Determination of acetylcholinesterase (AChE) activity}

Activity of AChE in homogenate was determined according to the method of Ellman et al. (1961) using ATC as substrate. The reaction mixture contained $0.4 \mathrm{ml}$ brain homogenate $(0.02 \mathrm{~g} / \mathrm{ml}), 2.6 \mathrm{ml}$ phosphate buffer $(0.1 \mathrm{M}, \mathrm{pH} 8.0), 100 \mu \mathrm{l}$ DTNB. The reaction mixture was mixed by bubbling air, and placed in the spectrophotometer. Once the reaction content was stable, the absorbance was noted at $412 \mathrm{~nm}$ for the basal reading followed by addition of $5.2 \mu \mathrm{l}$ of ATC to this cuvette. Any change in absorbance was recorded from zero time followed by $10 \mathrm{~min}$ at $25^{\circ} \mathrm{C}$. The activity of AChE was expressed as $\mu \mathrm{mol} / \mathrm{min} / \mathrm{g}$ of brain tissue.

\section{Determination of 5-HT and 5-HIAA}

For determination of 5-HT and 5-HIAA homogenization of frozen brains was carried out in an extraction medium using an electrical homogenizer (Polytron; Kinematica). The neurochemical analysis was done to assess concentrations of 5-hydroxytryptamine (5-HT), and their metabolites 5-hydroxyindoleacetic acid (5-HIAA) brain as described by Samad and Haleem (2009). Reversed-phase High Performance Liquid Chromatography (HPLC) with an electrochemical detector (Shimadzu LEC 6Adetector) was performed to detect levels of biogenic amines in brain samples. The EC detector was operated at a potential of $+0.8 \mathrm{~V}$. The stationary phase used for separation is a $5-\mu$ Shim-pack ODS column having an internal diameter of $4.0 \mathrm{~mm}$ and a length of $150 \mathrm{~mm}$. The mobile phase that passes through a column with a pump pressure of 2,000-3,000 psi contains octyl sodium sulfate $(0.023 \%)$ in $0.1 \mathrm{M}$ phosphate buffer at $\mathrm{pH} 2.9$.

\section{Statistical analysis}

The results are presented as mean $\pm \mathrm{SD}$ for six animals in each group. The statistical significant differences were evaluated by Tukey's test following two-way ANOVA using SPSS version 20. Value of $\mathrm{p}<0.05$ was considered as a significant difference.

\section{Results}

Effects of pre-administration of Quer on anxiety profile in unstressed and stressed mice observed in light dark activity box

Figure 1 shows the effects of pre-administration of Quer on anxiety profile in unstressed and stressed mice observed in light dark box. Data for time spent in light box analyzed by two-way ANOVA revealed that the effect of stress $[\mathrm{F} \quad(1,20)=34.80, \quad \mathrm{p}<0.01]$, Quer $[\mathrm{F}(1,20)=215.53, \mathrm{p}<0.01]$, and interaction of stress $\times$ Quer interaction $[\mathrm{F}(1,20)=19.68, \quad \mathrm{p}<0.01] \quad$ were significant. Post-hoc analysis by Tukey's test showed that $2 \mathrm{~h}$ immobilization stress significantly decreased $(\mathrm{p}<0.01)$ time spent in light box in vehicle treated mice as compared to unstressed animals. Time spent in light box significantly increased $(\mathrm{p}<0.01)$ in Quer treated unstressed and stressed mice as compared to controls.

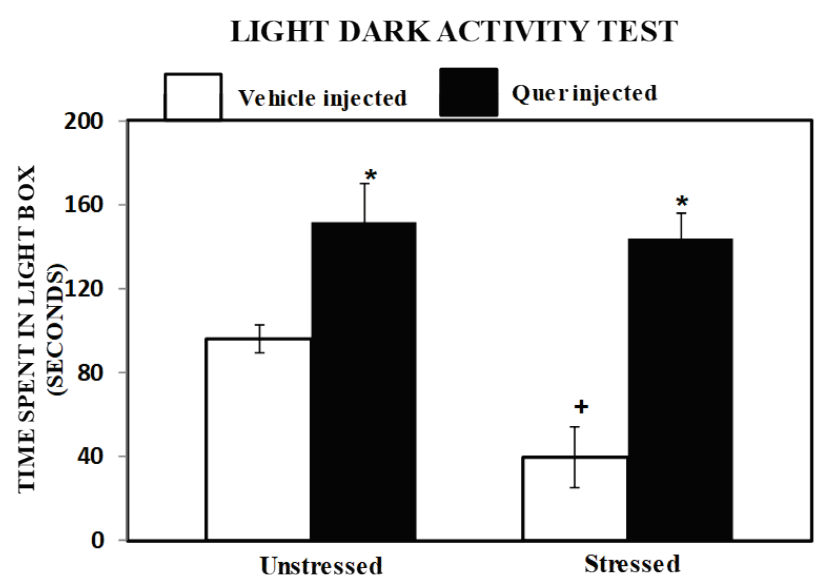

Fig. 1. Time spent in light box in light dark box test for the vehicle and Quer treated unstressed and stressed groups following single $2 \mathrm{~h}$ immobilization stress. Values are mean $\pm \mathrm{SD}$ $(n=6)$. Data was analyzed by Tukey's test following two-way ANOVA. Statistical difference is represented as $* p<0.05$ versus respective control and ${ }^{+} p<0.05$ vs. unstressed groups.

Effects of pre-administration of Quer on anxiety profile in unstressed and stressed mice observed in EPM

Figure 2 shows the effects of pre-administration of Quer on anxiety profile in unstressed and stressed mice observed in EPM. Data for time spent in open arm analyzed by two-way ANOVA revealed that the effect of stress $[\mathrm{F}(1,20)=39.95, \mathrm{p}<0.01]$, Quer $[\mathrm{F}(1,20)=149.60$, $\mathrm{p}<0.01]$, and interaction of stress $\times$ Quer interaction $[\mathrm{F}(1,20)=24.62, \mathrm{p}<0.01]$ were all significant. Post hoc analysis by Tukey's test showed that $2 \mathrm{~h}$ immobilization stress significantly decreased $(p<0.01)$ time spent in open 
arm in vehicle treated mice as compared to unstressed controls. Time spent in open arm significantly increased $(\mathrm{p}<0.01)$ in Quer treated unstressed and stressed mice as compared to controls.

Effects of Quer administration following acute immobilization stress on immobility in FST

The effects of Quer administration following acute immobilization stress on immobility in FST is shown in Figure 3. In FST the effect of stress $[F(1,20)=73.38, p<0.01]$, Quer $[F(1,20)=429.31, p<0.01]$ and stress $\times$ Quer interaction $[\mathrm{F}(1,20)=106.57, \mathrm{p}<0.01]$ were significant following two-way ANOVA. Post hoc analysis by Tukey's test found that repeated pre-administration of Quer significantly decreased immobility time in unstressed $(\mathrm{p}<0.01)$ and stressed mice $(p<0.01)$. On the other hand, immobility time in FST was increased in vehicle+stressed animal.

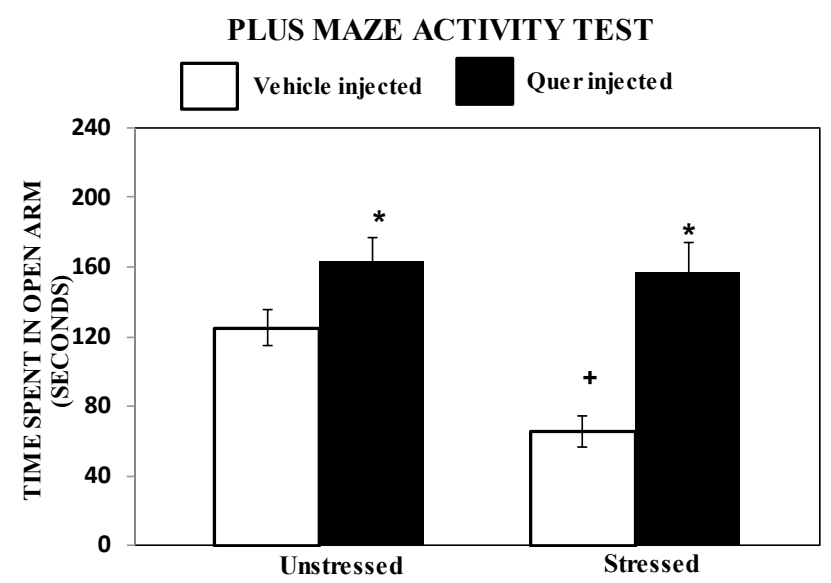

Fig. 2. Time spent in open arm in elevated plus maze test for the vehicle and Quer treated unstressed and stressed groups following single $2 \mathrm{~h}$ immobilization stress. Values are mean $\pm \mathrm{SD}$ $(n=6)$. Data was analyzed by Tukey's test following two-way ANOVA. Statistical difference is represented as $* p<0.05$ versus respective control and ${ }^{+} p<0.05$ versus unstressed groups.

Effects of pre-administration of Quer on memory function in vehicle and Quer treated stressed and unstressed mice

Figure 4 shows memory function that was determined by performing MWM activity in vehicle and Quer treated stressed and unstressed mice. The MWM activity is expressed as time to find the hidden platform performed immediately after training (acquisition) and $1 \mathrm{~h}$ (short term memory).

Results of acquisition analyzed by two-way ANOVA showed effects of stress $[\mathrm{F}(1,20)=2.29, \mathrm{p}=0.14]$, Quer $[\mathrm{F}(1,20)=0.13, \mathrm{p}=0.71]$ and interaction between the two factors $[F(1,20)=0.59, \mathrm{p}=0.44]$ were not significant.
Two-way ANOVA for short term memory showed that significant effects of stress $[F(1,20)=22.94, p<0.01]$ and Quer $[\mathrm{F}(1,20)=34.27, \quad \mathrm{p}<0.01]$, while interaction $[\mathrm{F}(1,20)=0.05, \mathrm{p}=0.82]$ was not significant. Post hoc analysis by Tukey's test demonstrated that pre administration of Quer produced non-significant effects on memory during acquisition. Whereas analysis of short term memory revealed that Quer significantly decrease the time to reach the hidden platform in stressed as well as unstressed mice. Similarly immobilization stress also decreased the time during analysis of short term memory.

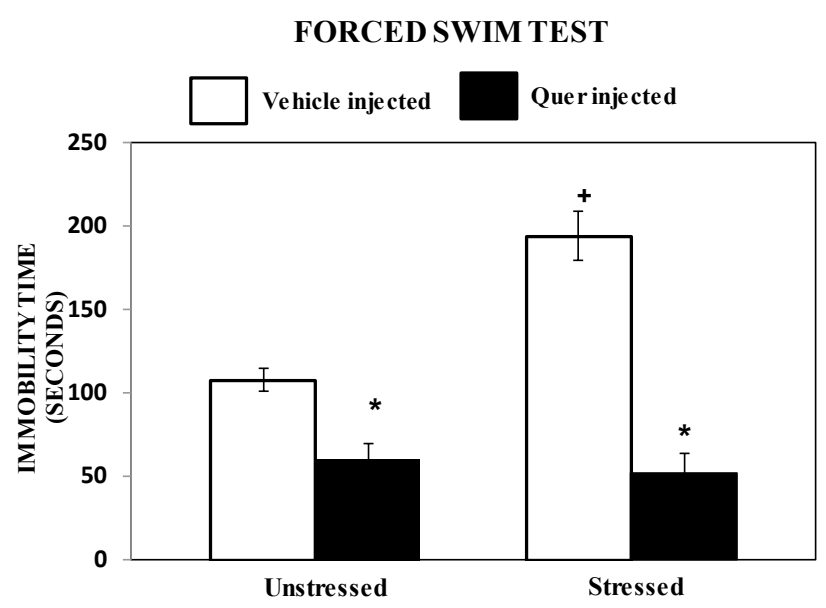

Fig. 3. Effect of Quer on depression like symptoms assessed by forced swim test in terms of immobility time (s) following single $2 \mathrm{~h}$ immobilization stress. Values are mean $\pm S D(n=6)$. Data was analyzed by Tukey's test following two-way ANOVA. Statistical difference is represented as $* p<0.05$ versus respective control and ${ }^{+} p<0.05$ versus unstressed groups.

Effects of Quer administration following single 2-h immobilization stress on brain MDA activity

Figure 5 shows the effects of Quer following immobilization stress on MDA levels. Data was analyzed by two-way ANOVA exhibited a significant effect of Quer $[\mathrm{F}(1,20)=12.79, \mathrm{p}<0.01]$ and interaction between stress and Quer $[\mathrm{F}(1,20)=12.27, \mathrm{p}<0.01]$. While, effect of stress $[\mathrm{F}(1,20)=0.007, \mathrm{p}>0.05]$ was not significant. Post hoc analysis by Tukey's test showed that 2-h immobilization increased MDA levels in vehicle+stressed animals. On the other hand, administration of Quer decreased lipid peroxidation in stressed than vehicle treated animals.

Effects of Quer administration following single 2-h immobilization stress on brain antioxidant enzyme activity

Figure 6 shows the effects of pre-administration of Quer on antioxidant enzyme in unstressed and stressed 
animals. Data on the activity of SOD was analyzed by two-way ANOVA exhibited a significant effect of Quer $[F(1,20)=61.10, p<0.01]$, stress $[F(1,20)=5.33, p<0.05]$ and interaction between stress and Quer $[\mathrm{F}(1,20)=16.94$, $\mathrm{p}<0.01]$. Post hoc analysis by Tukey's test showed that stress decreased the activity of SOD in vehicle treated animals. On the contrary, administration of Quer increased the activity of SOD in stressed than vehicle treated animals.
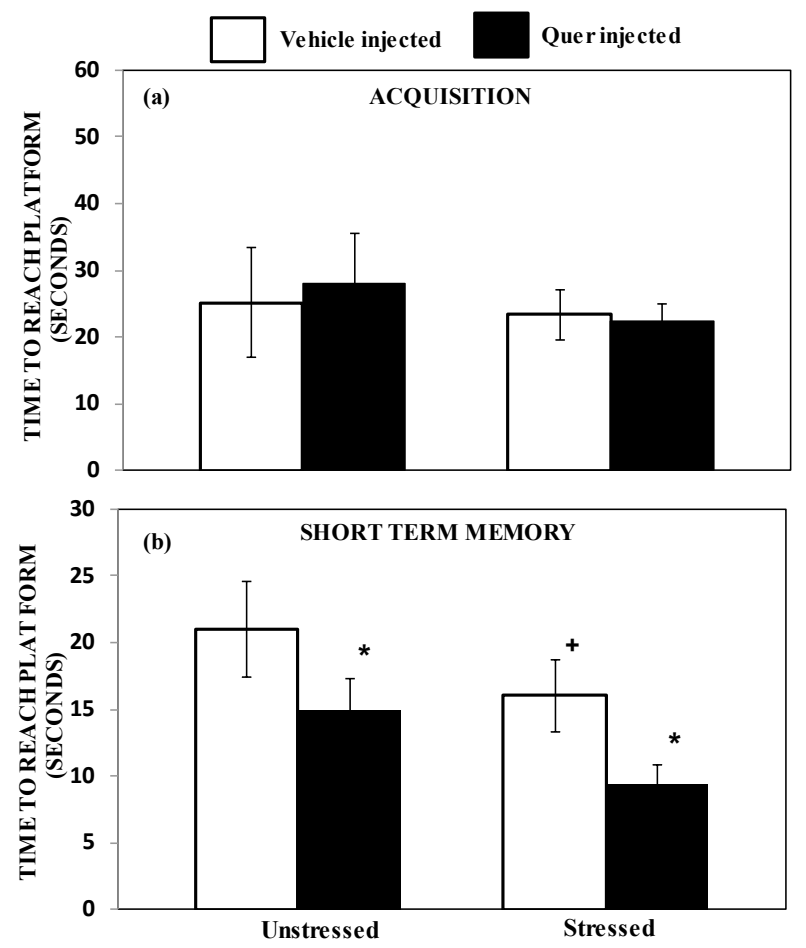

Fig. 4. Effect of Quer administration following single $2 \mathrm{~h}$ immobilization stress on (a) acquisition ad (b) short term memory in terms of escape latency (s) assessed by Morris water maze. Values are mean $\pm S D(n=6)$. Data was analyzed by Tukey's test following two-way ANOVA. Statistical difference is represented as $* p<0.05$ versus respective control and ${ }^{+} p<0.05$ versus unstressed groups.

Data on the activity of CAT was analyzed by two-way ANOVA exhibited a significant effect of Quer $[F(1,20)=28.42, p<0.01]$, and interaction between the two factors $[F(1,20)=21.34, \quad \mathrm{p}<0.01]$. Effect of stress $[\mathrm{F}(1,20)=3.17, \mathrm{p}=0.09]$ was not significant. Post hoc analysis by Tukey's test showed pre-administration of Quer increased the activity of CAT in stressed than vehicle + stressed animals. In addition activity of CAT was also increased in Quer treated stressed than unstressed animals. The data indicating that pre-administration of Quer increased the activity of antioxidant enzymes in stressed mice.

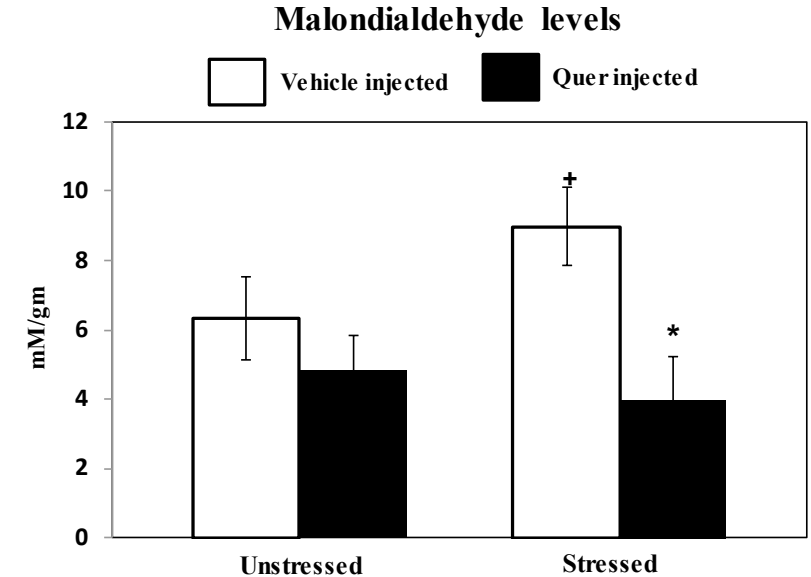

Fig. 5. Effect of Quer administration following single $2 \mathrm{~h}$ immobilization stress on brain MDA activity. Values are mean \pm SD $(n=6)$. Data was analyzed by Tukey's test following two-way ANOVA. Statistical difference is represented as $* p<0.05$ versus respective control and ${ }^{+} p<0.05$ versus unstressed groups.

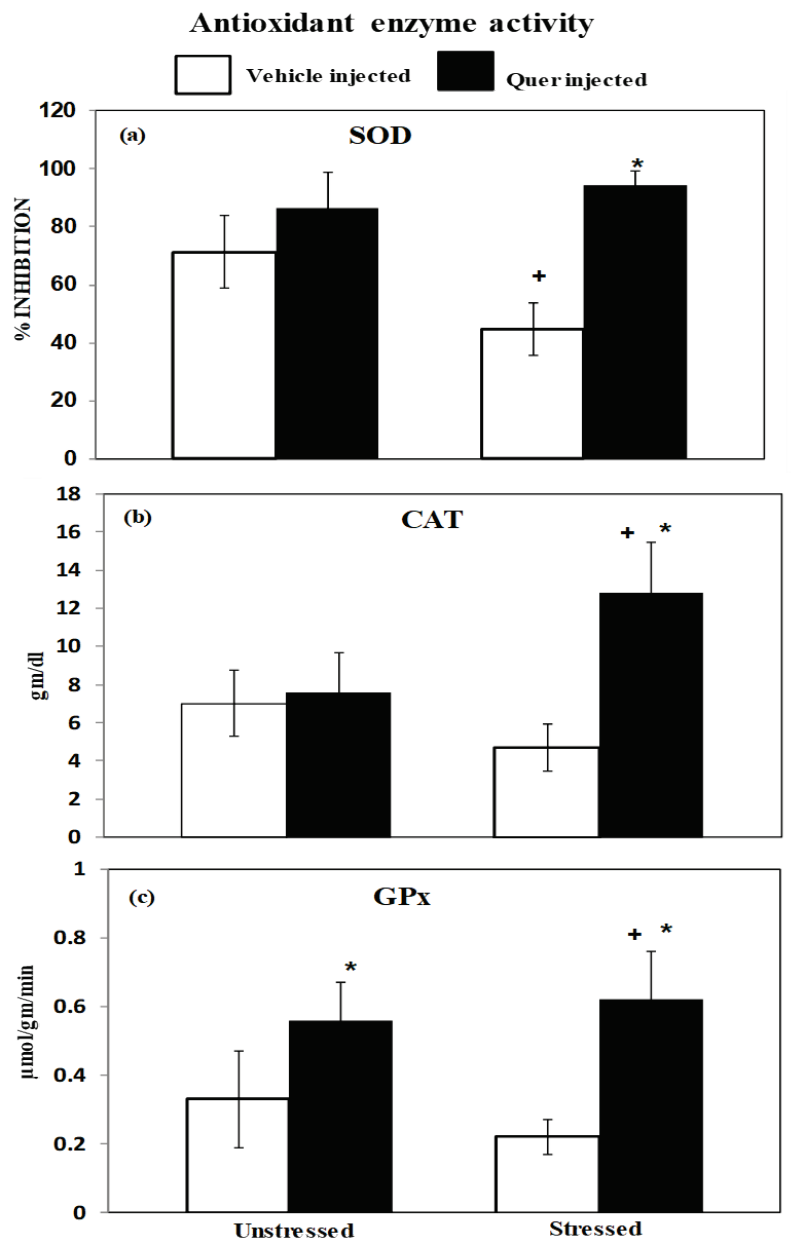

Fig. 6. Effect of Quer administration following single $2 \mathrm{~h}$ immobilization stress on brain SOD (a), CAT (b) and GPx (c) activity. Values are mean $\pm S D(n=6)$. Data was analyzed by Tukey's test following two-way ANOVA. Statistical difference is represented as $* p<0.05$ versus respective control and ${ }^{+} p<0.05$ versus unstressed groups. 
Data on the activity of GPx was analyzed by two-way ANOVA exhibited a significant effect of Quer $[F(1,20)=41.03, p<0.01]$. Effect of stress $[F(1,20)=0.27$, $\mathrm{p}=0.60]$ and interaction between stress and Quer $[\mathrm{F}(1,20)=3.03, \mathrm{p}=0.09]$ were not significant. Post hoc analysis by Tukey's test showed that administration of Quer significantly increased the activity of GPx in stressed and unstressed than their counterparts. Similarly, Quer administration also increases GPx activity in stressed animals as compare to unstressed animals.

Effects of Quer administration following single 2-h immobilization stress on brain AChE activity

Figure 7 shows the brain AChE activity $(\mu \mathrm{mol} / \mathrm{min} / \mathrm{g}$ ) that was assayed to find out the cholinergic function. Two way ANOVA for the attained data validated a significant effect of Quer $[\mathrm{F}(1,20)=12.09$, $\mathrm{p}<0.05]$ and interaction between stress $\mathrm{x}$ Quer $[F(1,20)=20.80, p<0.01]$ whereas, stress $[F(1,20)=3.12$, $\mathrm{p}=0.09]$ produced a significant effect. Post hoc analysis by Tukey's test showed pre-administration of Quer significantly decreased $(p<0.01)$ the activity of $\mathrm{AChE}$ in unstressed than vehicle. The levels of AChE activity was also decreased in vehicle + stressed animals.

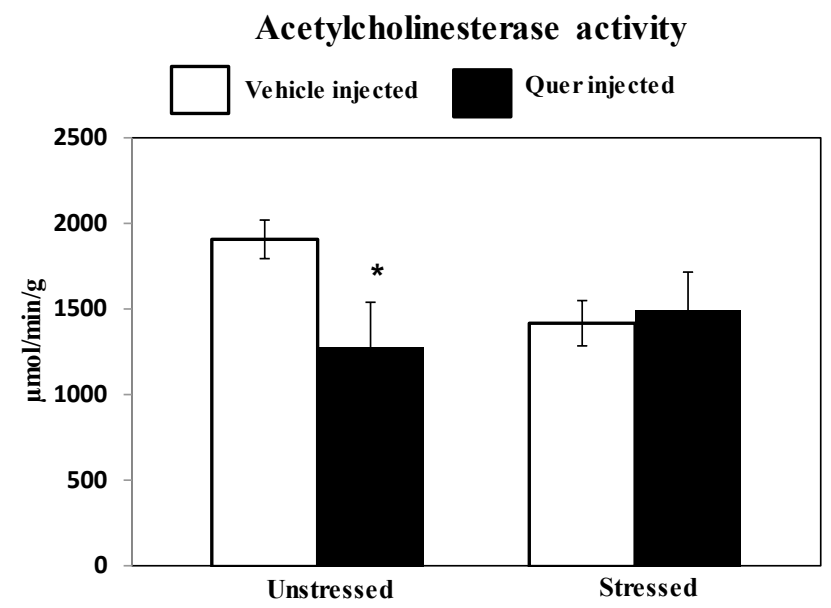

Fig. 7. Effect of Quer administration following single $2 \mathrm{~h}$ immobilization stress on brain AChE activity. Values are mean \pm SD $(n=6)$. Data was analyzed by Tukey's test following twoway ANOVA. Statistical difference is represented as $* p<0.05$ versus respective control and ${ }^{+} p<0.05$ versus unstressed groups.

Effects of Quer administration following single 2-h immobilization stress on brain ACh levels

Figure 8 shows the effects of administration of Quer on brain ACh level in unstressed and stressed animals. Two way ANOVA for the attained data validated a significant effect of stress $[F(1,20)=22.09$, $\mathrm{p}<0.01]$, and Quer $[\mathrm{F}(1,20)=11.12, \mathrm{p}<0.01]$. While interaction between two factors $[\mathrm{F}(1,20)=0.04, \mathrm{p}=0.83]$ was not significant. Post hoc analysis by Tukey's test showed 2-h immobilization stress significantly increased Ach levels in vehicle stressed than unstressed animals. Furthermore administration of Quer also significantly increased Ach levels in the brain of stressed than unstressed mice.

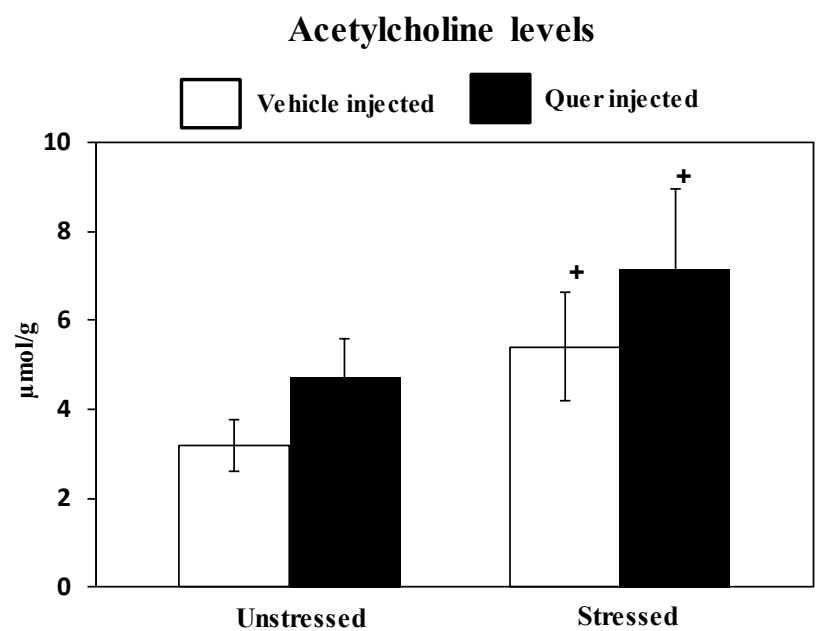

Fig. 8. Effect of Quer administration following single $2 \mathrm{~h}$ immobilization stress on brain ACh Values are mean \pm SD $(n=6)$. Data was analyzed by Tukey's test following two-way ANOVA. Statistical difference is represented as $* p<0.05$ versus respective control and ${ }^{+} p<0.05$ versus unstressed groups.

Effects of Quer following immobilization stress on brain 5-HT and 5-HIAA levels

Figure 9 shows the effects of Quer following immobilization stress on brain 5-HT and 5-HIAA levels. Data on 5-HT levels was analyzed by two-way ANOVA exhibited a significant effect of Quer $[F(1,20)=8.06$, $\mathrm{p}<0.05]$ stress $[\mathrm{F}(1,20)=26.80, \mathrm{p}<0.01]$. Interaction between the two factors $[\mathrm{F}(1,20)=0.355, \mathrm{p}=0.55]$ was not significant. Post hoc analysis by Tukey's test showed that 2-h immobilization increased 5-HT levels in vehicle and Quer treated stressed animals.

Data on 5-HIAA levels was analyzed by two-way ANOVA exhibited a significant effect of Quer $[F(1,20)=17.8, \quad p<0.01], \quad$ and stress $\quad[F(1,20)=29.5$, $\mathrm{p}<0.01]$. Interaction between stress x Quer $[\mathrm{F}(1,20)=0.19$, $\mathrm{p}=0.66]$ was not significant. Post hoc analysis by Tukey's test showed that 2-h immobilization increased 5-HIAA levels in vehicle and Quer treated stressed animals. On the other hand immobilization-induced increases of 5-HIAA levels were decreased in Quer treated stressed animals. 

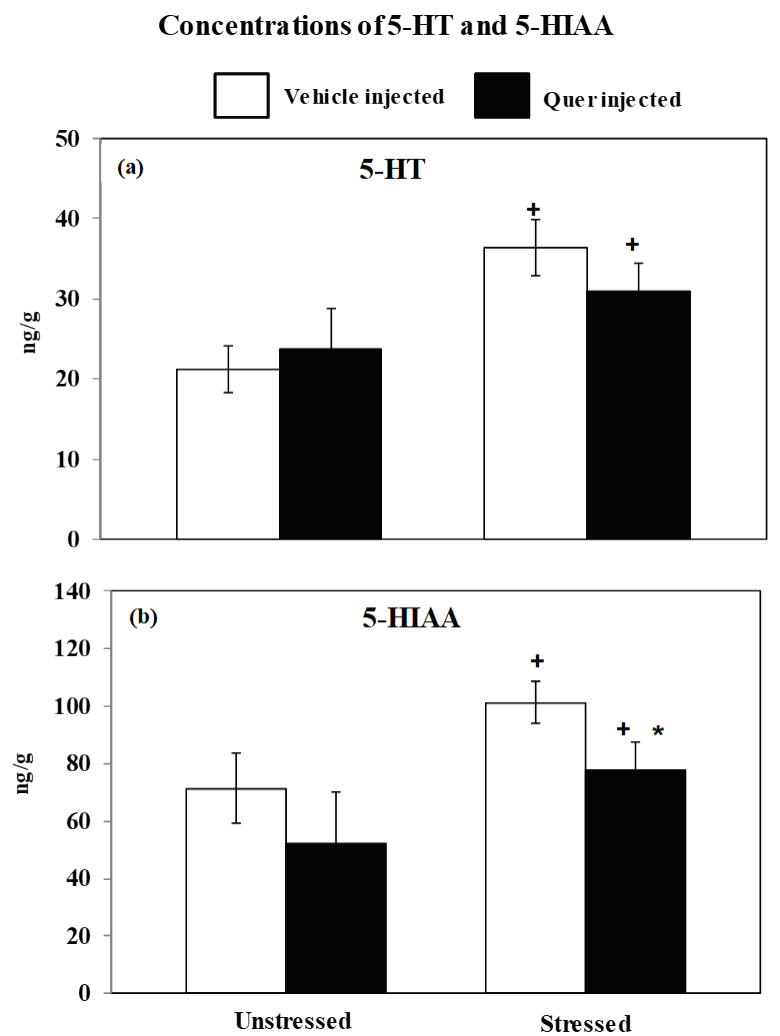

Fig. 9. Effect of Quer administration following single $2 \mathrm{~h}$ immobilization stress on (a) brain 5-HT and (b) 5-HIAA. Values are mean $\pm \operatorname{SD}(n=6)$. Data was analyzed by Tukey's test following two-way ANOVA. Statistical difference is represented as $* p<0.05$ versus respective control and ${ }^{+} p<0.05$ versus unstressed groups.

\section{Discussion}

Research works on experimental animals demonstrate that an uncontrollable stress situation produced neurochemical changes and behavioral deficits (Samad and Haleem 2009). Stress induced behavioral deficits in experimental animals are generally used as animal model of depression (Samad et al. 2006). Previously, it has been reported that Quer has antioxidant potential (Nayabi et al. 2015), antidepressant (Demir et al. 2016, Holzmann et al. 2015) and memory enhancing effects (Mereci et al. 2016, Islam et al. 2013). Acute stress also boosts memory functions. Our results show that 2-h immobilization stress produced anxiety like behavior in LDA (Fig. 1) and EPM (Fig. 2), and depression-like behavior in FST (Fig. 3). Both anxietyand depression-like behavior were reversed by prior administration of Quer (Figs 1,2 and 3) due to antioxidant potential. It has been extensively reported that stress situation involved in generation of free radicals (Sharma et al. 2015) and suppress antioxidant mechanism of the body (Nayabi et al. 2015), The natural cellular antioxidant enzymes include SOD, which scavenges the superoxide ion by speeding up its dismutation; CAT, a heme containing enzyme which removes hydrogen peroxide; and GPx, a selenium-containing enzyme, which scavenges hydrogen peroxide and other peroxides (Blake et al. 1987). In our study the levels of MDA (Fig. 5) and SOD (Fig. 6) were significantly altered while CAT and GPx were non-significantly decreased, suggesting increased oxidative stress produced an inhibitory effect on SOD levels in these animals. The significant correlation between MDA and SOD in vehicle treated unstressed and stressed animals may be attributed the immobilization stressed induced oxidative stress which may involved in alteration of antioxidant enzymes activities. Quer is a powerful antioxidant as extensively reported and possessing reactive oxygen species scavenging activity (Nayabi et al. 2015, Sharma et al. 2015). It is reported that Quer enhances the antioxidant enzymes activity and diminishes the lipid peroxidation (Mercer et al. 2005, Haleagrahara et al. 2009). As observed in the present study due to antioxidant potential Quer attenuates the behavioral deficits following 2-h immobilization stress and also normalizes the SOD, CAT and GPx activity with reduction in oxidative stress. The aforementioned results suggest that protecting effects of Quer may be at least being in a part due to its antioxidant effect.

5-HT levels have been reported to increase following immobilization stress in whole brain (Samad et al. 2006) and various brain regions (Haleem and Parveen 1994, Moa et al. 2008) of rats. An ample evidence indicate that dysfunction of serotonergic neurotransmission in CNS is involved in the development of depression, anxiety and memory disorders (Hugus et al. 2002, Naughten et al. 2000). Increased level of brain 5-HT enhances memory (Haider et al. 2006) and produced antidepressant effects whereas decreased level of brain 5-HT impairs cognitive performance (Porter et al. 2003) and produced antidepressant effects. It was observed in this study that administration of Quer increases 5-HT levels in stressed than vehicle treated animals consistent with the recent study (Liaqat et al. 2018). Hence, it can be suggested that administration of Quer increases cognitive performance and antidepressant due to increase in 5-HT levels. Recently, it has been studied that Quer improves sertonergic functions (Liaqat et al. 2018). Earlier studies have also been shown that catabolism of 5-HT by MAO involved in the production 
of free radicals production (Bianchi et al. 2005, Antkiewicz-Michaluk et al. 2014) which produces oxidative stress and associated with behavioral deficits development following immobilization stress. Quer which is reported as MAO inhibitor (Bandaruk et al. 2012) may also be involved in the decreasing catabolism of 5-HT (Fig. 9), which could be reduced the free radical generation and decreased the oxidative stress-induced (Figs 5, 6) behavioral alteration (Figs 1, 2, 3 and 4) following immobilization stress, Though, under immobilization stress principal actions of repeated administration of Quer on 5-HT may be presynaptical, which inhibits MAO (Bandaruk et al. 2012) and increase the availability of 5-HT in the synapse. This may stimulate the regulation of 5-HT release via presynaptic 5-HT auto-receptors in mice hippocampus causing the decreased release of 5-HT. These actions of Quer may serve to correct5-HT function abnormalities under stress.

Ach is also one of the key neurotransmitter concerned in cognition. Previously it has reported that acute stress increases the release of acetylcholine in the hippocampus (Imperato et al. 1991) and modulates the genes that regulate acetylcholine availability after stress and blockade of AChE (Kafur et al. 1998). AChE is one of the important enzymes to determine the cholinergic function (Papandreou et al. 2011). Extensive research studies have been reported the association between $\mathrm{AChE}$ and memory performance, but still there is need of more studies because definite pattern for this association is not clear. The altered memory function following neonatal iron exposure (Perez et al. 2010) and acute and immobilization stress (Das et al. 2000) decreased AChE activity. A pronounced increase in transfer latency time was observed in passive avoidance test as compared to that of control and chronically stressed groups, indicating a better cognitive ability in these rats (Das et al. 2000). The result on AChE activity in the present study are also in agreement with the previous (Fig. 7), suggesting that Quer which known as inhibitor of AChE activity (Islam et al. 2013) and improves cholinergic function (Liaqat $e t$ al. 2018) may be involved in availability of ACh (Fig. 8) to strengthen the memory function. Quer and acute stress have demonstrated to enhance the memory performance, which is also observed in the present study (Fig. 4); however, a novel finding is that Quer may enhance acute stress-induced increase in memory function.

In addition, it can be postulated that Quer which is involved in normalization of brain serotonergic function, thereby improving memory function in mice. The memory enhancing effects of acute stress with prior administration of Quer may also be explainable in the same milieu as increased cholinergic function (Fig. 8) may also activate serotonergic system (Fig. 9) to boosts up the cognition.

In conclusion, we evaluated the anxiolytic, antidepressant and memory enhancing effects of Quer following 2-h immobilization stress in mice. The results revealed that pre-administration of Quer attenuated stress-induced behavioral deficits strongly by its antioxidant potential. Furthermore, Quer also involves in the regulation of serotonergic and cholinergic functions, produces antidepressant and anxiolytic effect, and boosts memory performance. The present study therefore, emphasizes the use of dietary sources rich in Quer contents and/or supplementation of Quer as an effective remedy for daily stress life events.

\section{Conflict of Interest}

There is no conflict of interest.

\section{Acknowledgements}

This work was supported by a research grant from Bahauddin Zakariya University, Multan, Pakistan.

\section{References}

ABDALLA FH, CARDOSO AM, PEREIRA LB, SCHMATZ R, GONÇALVES JF, STEFANELLO N, FIORENZA AM, GUTIERRES JM, SERRES JD DA S, ZANINI D, PIMENTEL VC, VIEIRA JM, SCHETINGER MRC, MORSCH VM, MAZZANTI CM: Neuroprotective effect of quercetin in ectoenzymes and acetylcholinesterase activities in cerebral cortex synaptosomes of cadmium-exposed rats. Mol Cell Biochem 381: 1-8, 2013.

ABDALLA FH, SCHMATZ R, CARDOSO AM, CARVALHO FB, BALDISSARELLI J, DE OLIVEIRA JS, ROSA MM, GONÇALVES NUNES MA, RUBIN MA, DA CRUZ IBM, BARBISAN F, DRESSLER VL, PEREIRA LB, SCHETINGER MRC, MORSCH VM, GONÇALVES JF, MAZZANTI CM: Quercetin protects the impairment of memory and anxiogenic-like behavior in rats exposed to cadmium: Possible involvement of the acetylcholinesterase and $\mathrm{Na}+$, K+-ATPase activities. Physiol Behav 135: 152-167, 2014. 
ALVES De ALMEIDA E, CELSO DIAS BAINY A, PAULA DE MELO LOUREIRO A, REGINA MARTINEZ G, MIYAMOTO S, ONUKI J, FUJITA BARBOSA L, CARRIÃO MACHADO GARCIA C, MANSO PRADO F, ELIZA RONSEIN G, ALEXANDRE SIGOLO C, BARBOSA BROCHINI C, MARIA GRACIOSO MARTINS A, HELENA GENNARI DE MEDEIROS M, DI MASCIO P: Oxidative stress in Perna perna and other bivalves as indicators of environmental stress in the Brazilian marine environment: Antioxidants, lipid peroxidation and DNA damage. Comp Biochem Physiol A Mol Integr Physiol 146: 588-600, 2007.

ANTKIEWICZ-MICHALUK L, WASIK A, EDYTA MOZDZEN E, ROMANSKA I, MICHALUK J: Antidepressantlike effect of tetrahydro isoquinoline amines in the animal model of depressive disorder induced by repeated administration of a low dose of reserpine: Behavioral and neurochemical studies in the rat. Neurotox Res 26: 85-98, 2014.

AUGUSTINSON KB: Assay methods for cholinesterases. In: Methods of Biochemical Analysis. Glick D (ed.), Interscience Publishers Inc., New York, 1957, pp 1-63.

BANDARUK Y, MUKAI R, KAWAMURA T, NEMOTO H, TERAO J: Evaluation of the inhibitory effects of quercetin-related flavonoids and tea catechins on the monoamine oxidase-A reaction in mouse brain mitochondria. J Agric Food Chem 60: 10270-10277, 2012.

BIANCHI P, KUNDUZOVA O, MASINI E, CAMBON C, BANI D, RAIMONDI L, SEGUELAS MH, NISTRI S, COLUCCI W, LEDUCQ N, PARINI A: Oxidative stress by monoamine oxidase mediates receptor independent cardiomyocyte apoptosis by serotonin and post ischemic myocardial injury. Circulation 112: 3297-3305, 2005.

BLAKE DR, ALLEN RE, LUNEE J: Free radicals in biological systems: a review oriented to the inflammatory process. Br Med Bull 43: 371-385, 1987.

BORYS B: Psychology in contemporary medicine. (In Polish) Pol Merkur Lekarski 25 (Suppl 1): 35-39, 2008.

CAHILL L, GORSKI L, LE K: Enhanced human memory consolidation with post-learning stress: interaction with the degree of arousal at encoding. Learn Mem 10: 270-274, 2003.

CHOW CK, TAPPEL AL: An enzymatic protective mechanism against lipid peroxidation damage to lungs of ozoneexposed rats. Lipids 7: 518-524, 1972.

DAS A, KAPOOR K, SAYEEPRIYADARSHINI AT, DIKSHIT M, PALIT G, NATH C: Immobilization stressinduced changes in brain acetylcholinesterase activity and cognitive function in mice. Pharmacol Res 42 : 213-217, 2000.

DEMIR EA, GERGERLIOGLU HS, OZ M: Antidepressant-like effects of quercetin in diabetic rats are independent of hypothalamic-pituitary-adrenal axis. Acta Neuropsychiatr 28: 23-30, 2016.

ELLMAN GL, COURTNEY KD, ANDRES V, FEATHERSTONE RM: A new and rapid colorimetric determination of acetylcholinesterase activity. Biochem Pharmacol 7: 88-95, 1961.

FERNANDEZ SP, WASOWSKI C, LOSCALZO LM, GRANGER RE, JOHNSTON GA, PALADINI AC, MARDER M: Central nervous system depressant action of flavonoid glycosides. Eur J Pharmacol 539: 168-176, 2006.

FLOHE L, GUNZLER WA: Assays of glutathione peroxidase. Methods Enzymol 105: 114-121, 1984.

GÜMÜŞLÜ S, SARIKÇIOĞLU SB, SAHIN E, YARGIÇOĞLU P, AĞAR A: Influences of different stress models on the antioxidant status and lipid peroxidation in rat erythrocytes. Free Radic Res 36: 1277-1282, 2002.

HAIDER S, TABASSUM S, PERVEEN T, ALI S, SALEEM S, KHAN AK, HALEEM DJ: Age-related decrease in striatal DA produces cognitive deficits in male rats. J Pharm Nutr Sci 1: 20-27, 2011.

HAIDER S, KHALIQ S, AHMED SP, HALEEM DJ: Long term tryptophan administration enhances cognitive performance and increases 5HT metabolism in the hippocampus of female rats. Amino Acids 31: 421-425, 2006.

HALEAGRAHARA N, RADHAKRISHNAN A, LEE N, KUMAR P: Flavonoid quercetin protects against swimming stress-induced changes in oxidative biomarkers in the hypothalamus of rats. Eur J Pharmacol 621: 46-52, 2009.

HALEEM DJ, PERVEEN T: Brain regional serotonin synthesis following adaptation to repeated restraint. Neuroreport 5: 1785-1788, 1994.

HALLIWELL B, GUTTERIDGE JMC: Oxygen radicals and the nervous system. Trends Neurosci 8: 22-26, 1985. 
HARAGUCHI S, KOYAMA T, HASUNUMA I, OKUYAMA S, UBUKA T, KIKUYAMA S, DOREGO JL, VAUDRY H, TSUTSUI K: Acute stress increases the synthesis of 7-hydroxypregnenlone, a new key neurosteroid stimulating locomotor activity, through corticosterone action in newts. Endocrinology 153: 794-805, 2012.

HAVSTEEN BH: The biochemistry and medical significance of the flavonoids. Pharmacol Ther 96: 67-202, 2002.

HERRERA-RUIZ M, ZAMILPA A, GONZALEZ-CORTAZARM, REYES-CHILPA R, LEON E, GARCIA MP, TORTORIELLO J, HUERTA-REYES M: Antidepressant effect and pharmacological evaluation of standardized extract of flavonoids from Byrsonima crassifolia. Phytomedicine 18: 1255-1261, 2011.

HESTRIN S: The reaction of acetylcholine and other carboxylic and derivatives with hydroxylamine and its analytical application. J Biol Chem 180: 249-261, 1949.

HOLZMANN I, DA SILVA LM, CORRÊA DA SILVA JA, STEIMBACH VMB, DE SOUZA MM: Antidepressantlike effect of quercetin in bulbectomized mice and involvement of the antioxidant defenses, and the glutamatergic and oxidonitrergic pathways. Pharmacol Biochem Behav 136: 55-63, 2015.

HUGHES JH, GALLAGHER P, YOUNG AH: Effects of acute tryptophan depletion on cognitive function in euthymic bipolar patients. Eur Neuropsychopharmacol 12: 123-128, 2002.

IMPERATO A, PUGLISI-ALLEGRA S, CASOLINI P, ANGELUCCI L: Changes in brain dopamine and acetylcholine release during and following stress are independent of the pituitary-adrenocortical axis. Brain Res 538: 111-117, 1991.

ISLAM MR, ZAMAN A, JAHAN I, CHAKRAVORTY R, CHAKRABORTY S: In silico QSAR analysis of quercetin reveals its potential as therapeutic drug for Alzheimer's disease. J Young Pharmacist 5: 173-179, 2013.

JAGER AK, SAABY L: Flavonoids and the CNS. Molecules 16: 1471-1485, 2011.

JOËLS M, PU Z, WIEGERT O, OITZL MS, KRUGERS HJ: Learning under stress: How does it work? Trends Cogn Sci 10: 152-158, 2006.

KAWABATA K, KAWAI Y, TERAO J: Suppressive effect of quercetin on acute stress-induced hypothalamicpituitary-adrenal axis response in Wistar rats. J Nut Biochem 21: 374-380, 2010.

KAUFER D, FRIEDMAN A, SEIDMAN S, SOREQ H: Acute stress facilitates long-lasting changes in cholinergic gene expression. Nature 393: 373-377, 1998.

KUMAR A, GARG R, PRAKASH AK: Effect of St John's Wort (Hypericum per-foratum) treatment on restraint stressinduced behavioral and biochemical alteration in mice. BMC Complement Altern Med 10: 18, 2010.

KUMAR A, GOYAL R: Quercetin protects against acute immobilization stress-induced behaviors and biochemical alterations in mice. $J$ Med Food 11: 469-473, 2008.

LEE BH, HWANG SH, CHOI SH, SHIN TJ, KANG J, LEE SM, NAH SY: Quercetin inhibits alpha 3 beta 4 nicotinic acetylcholine receptor-mediated ion currents expressed in Xenopusoocytes. Korean J Physiol Pharmacol 15: 17-22, 2011.

LIAQUAT L, BATOOL Z, SADIR S, RAFIQ S, SHAHZAD S, PERVEEN T, HAIDER S: Naringenin-induced enhanced antioxidant defence system meliorates cholinergic neurotransmission and consolidates memory in male rats. Life Sci 194: 213-223, 2018.

LU J, WU DM, ZHENG YL, HU B, ZHANG ZF, SHAN Q, ZHENG ZH, LIU CM, WANG YJ: Quercetin activates AMP-activated protein kinase by reducing PP2C expression protecting old mouse brain against high cholesterol-induced neurotoxicity. $J$ Pathol 222: 199-212, 2010.

LUCAS LR, WANG CJ, MCCALL TJ, MCEWEN BS: Effects of immobilization stress on neurochemical markers in the motivational system of the male rat. Brain Res 1155: 108-115, 2007.

MACHADO DG, BETTIO LE, CUNHA MP, SANTOS AR, PIZZOLATTI MG, BRIGHENTE IM, RODRIGUES AL: Antidepressant-like effect of rutin isolated from the ethanolic extract from Schinus molle L. in mice: evidence for the involvement of the serotonergic and noradrenergic systems. Eur J Pharmacol 587: 163-168, 2008.

MACIEL RM, CARVALHO FB, OLABIYI AA, SCHMATZ R, GUTIERRES JM, STEFANELLO N, ZANINI D, ROSA MM, ANDRADE CM, RUBIN MA, SCHETINGER MR, MORSCH VM, DANESI CC, LOPES ST: Neuroprotective effects of quercetin on memory and anxiogenic-like behavior in diabetic rats: Role of ectonucleotidases and acetylcholinesterase activities. Biomed Pharmacother 84: 559-568, 2016. 
MERCER LD, KELLY BL, HORNE MK, BEART PM: Dietary polyphenols protect dopamine neurons from oxidative insults and apoptosis: Investigation in primary rat mesencephalic cultures. Biochem Pharmacol 69: 339-435, 2005.

MESRAM N, NAGAPURI K, BANALA RR, NALAGONI CR, KARNATI PR: Quercetin treatment against NaF induced oxidative stress related neuronal and learning changes in developing rats. J King Saud University Science 29: 221-229, 2017.

MOA B, FENGA N, RENNERA K, FORSTERB G: Restraint stress increases serotonin release in the central nucleus of the amygdala via activation of corticotropin-releasing factor receptors. Brain Res Bull 76: 493-498, 2008.

NABAVI SF, GIAN LRB, MARIA DC, NABAVI SM: Role of quercetin as an alternative for obesity treatment: you are what you eat! Food Chem 179: 305-310, 2015.

NASKAR S, ISLAM A, MAZUMDER UK, SAHA P, HALDAR PK, GUPTA M: In vitro and in vivo antioxidant potential of hydromethanolic extract of Phoenix dactylifera fruits. J Sci Res 2: 144-157, 2010.

NASSIRI-ASLM, ZAMANSOLTANI F, JAVADI A, GANJVAR M: The effects of rutin on a passive avoidance test in rats. Prog Neuropsychopharmacol Biol Psychiatry 34: 204-207, 2010.

NASSIRI-ASL M, MOGHBELINEJAD S, ABBASI E, YONESI F, HAGHIGHI MR, LOTFIZADEH M, BAZAHANG P: Effects of quercetin on oxidative stress and memory retrieval in kindled rats. Epilepsy Behav 28: $151-155,2013$.

NAUGHTEN M, MULROONEY JB, LEONARD BE: A role of the serotonin receptors in psychiatric disorders. Hum Psychopharmacol 15: 397-415, 2000.

NAQVI F, HAIDER S, BATOOL Z, PERVEEN T, HALEEM DJ: Sub-chronic exposure to noise affects locomotor activity and produces anxiogenic and depressive like behavior in rats. Pharmacol Rep 64: 64-69, 2012.

OITZL MS, REICHARDT HM, DE JOELS M, KLOET ER: Point mutation in the mouse glucocorticoid receptor preventing DNA binding impairs spatial memory. Proc Natl Acad Sci U S A 98: 12790-12795, 2001.

PAPANDREOU MA, TSACHAKI M, EFTHIMIOPOULOS S, CORDOPATIS P, LAMARI FN, MARGARITY M: Memory enhancing effects of saffron in aged mice is correlated with antioxidant protection. Behav Brain Res 219: 197-204, 2011.

PARI L, LATHA M: Protective role of Scorparia dulcis plant extract on brain antioxidant status and lipid peroxidation in STZ diabetic male Wistar rats. BMC Complement Alternat Med 6: 16, 2004.

PEREZ VP, DE LIMA MN, DE SILVA RS, DORNELLES AS, VEDANA G, BOGO MR, BONAN CD, SCHRÖDER $\mathrm{N}$ : Iron leads to memory impairment that is associated with a decrease in acetylcholinesterase pathways. Curr Neurovasc Res 7: 1522, 2010.

PORSOLT RD: Behavioral despair. In: Antidepressants: Neurochemical, Behavioral and Clinical Perspectives. ENNA SJ, MALICK JB, RICHELSON E (eds), Raven Press, New York, 1981, pp 121-139.

PORTER RJ, LUNN BS, O'BRIEN JT: Effects of acute tryptophan depletion on cognitive function in Alzheimer's disease and in the healthy elderly. Psychol Med 33: 41-49, 2003.

SAMAD N, MUNEER A, ULLAH N, ZAMAN A, AYAZ MM, AHMAD I: Banana fruit pulp and peel involved in antianxiety and antidepressant effects while invigorate memory performance in male mice: Possible role of potential antioxidants. Pak J Pharm Sci 30: 989-995, 2017.

SAMAD N, HALEEM DJ: Behavioral and neurochemical profile of m-CPP following exposure to single restraint stress in rat. Acta Neurol Belg 109: 24-31, 2009.

SAMAD N, PERVEEN T, HAIDER S, HALEEM MA, HALEEM DJ: Inhibition of restraint-induced neuroendocrine and serotonergic responses by buspirone in rats. Pharmacol Rep 58: 636-642, 2006.

SHARMA DR, SUNKARIA A, WANI WY, SHARMA RK, VERMA D, PRIYANKA K, BAL A, GILL KD: Quercetin protects against aluminium induced oxidative stress and promotes mitochondrial biogenesis via activation of the PGC-1a signaling pathway. Neurotoxicology 51: 116-137, 2015.

SUN SW, YU HQ, ZHANG H, ZHENG YL, WANG JJ, LUO L: Quercetin attenuates spontaneous behavior and spatial memory impairment in d-galactose-treated mice by increasing brain antioxidant capacity. Nut Res 27: $169-175,2007$. 
TONGJAROENBUANGAM W, RUKSEE N, CHANTIRATIKUL P, PAKDEENARONG N, KONGBUNTAD W, GOVITRAPONG P: Neuroprotective effects of quercetin, rutin and okra (Abelmoschusesculentus Linn.) in dexamethasone-treated mice. Neurochem Int 59: 677-685, 2011.

TSEILIKMAN VE, SINITSKY AI, POYARKOV KA, VOJDAEV EV: Effect of deprenyl on free radical oxidation in rat brain during immobilization stress. Bull Exp Biol Med 148: 856-858, 2009.

WATTANATHORN J, PHACHONPAI W, PRIPREM A, SUTHIPARINYANONT S: Intranasal administration of quercetin liposome decreases anxiety-like behavior and increases spatial memory. Am J Agril Biol Sci 2: 31-35, 2007.

YOSHINO S, HARA A, SAKAKIBARA H, KAWABATA K, TOKUMURA A, ISHISAKA A, KAWAI Y, TERAO J: Effect of quercetin and glucuronide metabolites on the monoamine oxidase-A reaction in mouse brain mitochondria. Nutrition 27: 847-252, 2011. 